\title{
GOVERNO À VISTA - A TRANSPARÊNCIA
}

Em seu Breviário dos Políticos, o cardeal Mazzarino transmitia uma mensagem aos governantes absolutistas da Itália, no século XVII: simula e dissimula. O conselho, embora hoje pareça insólito e repugnante, encontra ressonância no modelo de dominação (arcana imperii) que predominava à época na relação entre indivíduos (mais súditos do que cidadãos) e governantes. A percepção então amplamente disseminada de que o povo, enquanto massa de ignorantes, não possuía capacidade para o exercício da política, servia como pretexto para o seu alijamento dos assuntos públicos.

Nessa perspectiva, o exercício do poder ou domínio pelos príncipes residia na organização de uma instância aparentemente superior, cujos procedimentos e receitas não poderia revelar, de modo que a população acabaria internalizando a opacidade como o resultado de um governo naturalmente invisível. As decisões tomadas às escondidas, fora do alcance ótico e do poder de influência do povo marcou este período histórico.

Um feixe de luz, no entanto, pode esclarecer mais do que se imagina. Em janeiro de 1781, o equivalente ao que hoje chamamos Ministro da Fazenda, de Luís XVI, Jacques Necker, acendeu uma faísca de transparência em meio à sombra da monarquia francesa pré-revolucionária ao publicar um informe ao rei (Comptes rendu ao roi), no qual reunia, pela primeira vez, todos as informaçóes sobre o orçamento do Estado francês. A obra, embora escrita de forma bastante técnica, despertou enorme curiosidade no país e vendeu mais de 80 mil exemplares. Na "Carta ao Rei”, que servia como introdução, Necker falava dos benefícios que poder-se-ia extrair desta publicação. Para 
ele, a difusão das contas públicas estava destinada a construir uma sorte de coação positiva para a administração, pois "se reina a transparência, as dificuldades desaparecem e se crê então nas intenções dos administradores". ${ }^{348}$

A sequente revolução francesa promoveria a abertura da monarquia e a incipiência do princípio da publicidade dos atos governamentais, estabelecendo na Declaração dos Direitos do Homem e do Cidadão, de 1789, em seu art. 14, que todos os cidadãos detêm o direito de verificar a utilização de suas contribuições públicas.

Não obstante a importância da publicidade encontre acento desde Aristóteles, ${ }^{349}$ o qual afirmava que para prevenir a espoliação do tesouro público, era preciso que a receita fosse feita à vista do público, a experiência francesa colocara em evidência a necessidade de conhecer as questôes orçamentárias e o modo como os governantes alocavam e aplicavam os recursos provenientes da tributação. Abrindo um parêntese, o orçamento público constitui o berço da noção democrática de transparência como a entendemos e vivemos hoje. Difícil é crer que até os dias atuais não se lhe dá a devida publicidade.

Com a superação do Antigo Regime e a subsequente abertura democrática dos Estados modernos ao sufrágio universal, deslocando o nódulo de poder absoluto dos reis aos cidadãos, que o delegaria a agentes eleitos para atuar conforme o mandato conferido, exsurge o conceito de representação e os problemas de legitimidade. No entanto, o caráter público do poder ou, nas palavras de Bobbio, o poder em público, se manteve como um dos pressupostos fundamentais para distinguir o estado de direito do estado absoluto. Aliás, é o politólogo italiano quem lembra o nexo entre o princípio da representação e o caráter público do poder estabelecido por Carl Schmitt, segundo o qual a representação apenas poderia ocorrer na esfera da publicidade, uma vez que representar significa "tornar visível e tornar presente um ser invisível mediante um ser publicamente presente [o representante].”350

O bom funcionamento do sistema representativo deve proporcionar aos eleitores a faculdade de agir com conhecimento de causa, numa democracia que ultrapasse o seu aspecto meramente formal e eletivo. Se eleger consiste em escolher bons representantes, só é boa a escolha informada. O governo democrático pressupõe

348 NECKER, Jacques. Compte rendu ao roi (1781). In: ROSANVALLÓN, Pierre. El buen gobierno. Buenos Aires: Manantial, 2015.

349 ARISTÓTELES. A Política. Tradução de Nestor Silveira. São Paulo: Folha de São Paulo, 2010.

350 BOBBIO, Norberto. O futuro da democracia. Tradução de Marco Aurélio Nóbrega. 9. ed. São Paulo: Paz e Terra, 1999. 
um eleitorado armado pelo conhecimento sobre as propostas para o futuro governo, e sobre quem as implementará. Por outro lado, se falta a publicidade, pode haver eleições, deliberações, mas o povo não acreditará nelas, e com razão. ${ }^{351}$ Nesta hipótese, estaríamos apenas autorizando que o exercício da soberania fosse guiado pelo capricho de agentes sobre os quais não sabemos nada.

Desde então, o imperativo da publicidade evoluiu para uma noção mais ampla, de transparência, de sorte que a acessibilidade às informações públicas não mais estivesse restrita às questôes orçamentárias, mas a todas as esferas de atuação pública. Os cidadãos passam a reivindicar que se abra todas as caixas-pretas sobre os processos e decisões do Estado. $\mathrm{Na}$ esteira progressista de reconhecimento dos direitos e garantias fundamentais aos cidadãos, se destaca o direito de saber, ao qual corresponde o dever do Estado de promover o amplo e livre acesso às informações públicas como condição indispensável ao exercício da cidadania.

Hoje, qualquer estatuto de poder político fundado em bases democráticas não tolera o poder que se oculta - simula e dissimula, nas palavras de Mazzarino, consagrando a transparência como condição de legitimação das decisões, das práticas e dos atos governamentais. Em nossa Constituição, assegura-se o direito de acesso às informações de interesse coletivo ou geral (art. 5º, XIV e XXXIII, da CRFB/88), o que a Suprema Corte reforça ao afirmar que não se pode mais aceitar, como legítima, a democracia da ignorância, aquela na qual todos são absolutamente iguais no desconhecimento do que se passa no exercício do Poder. ${ }^{352}$

Mesmo assim, perduram os casos de órgãos governamentais que se negam a fornecer informações por classificá-las como "não públicas", sob a tutela de um sigilo que geralmente não existe, sem apresentar qualquer razão para a imposição do segredo, além da alegação usual de que se trata de informações estratégicas. Não obstante tenhamos uma das melhores leis de acesso à informação do mundo, a lei n. 12.527/2011, ainda lutamos para implementá-la na prática. ${ }^{353}$

351 GUIZOT, François. Des garanties legalé de la liberté de la presse (1818). In: ROSANVALLÓN, Pierre. El buen gobierno. Buenos Aires: Manantial, 2015.

352 STF, Rcl n. 11.949/RJ, Plenário, Rel. Min. Celso de Mello, decisão de 16.03.2017.

353 Diversos relatórios apontam graves problemas de efetiva aplicação da Lei de Acesso à Informação (Lei n. 12.527/2011) em território brasileiro. A saber: MICHENER, G.; MONCAU, L. F. M.; VELASCO, R. Estado Brasileiro e transparência: avaliando a aplicação da Lei de Acesso à Informação. Rio de Janeiro: FGV, 2014; MONCAU, L. F. M.; MICHENER, G.; BARROS, M.; VELASCO, R. Avaliação de transparência do Ministério Público. Rio de Janeiro: FGV, 2015; MICHENER, G. Transparência local no Brasil: avaliando a aplicação da lei de acesso nos estados e nas grandes cidades. Rio de Janeiro: FGV, 2016. 
- Finanças públicas: travessia entre o passado e o futuro

Minha pretensão, ao iniciar este tópico com uma digressão histórica acerca do princípio da transparência, foi mostrar que a sociedade caminha invariavelmente no sentido de promover a progressiva abertura das estruturas de Estado, como uma flor de lótus, que se emerge para receber o sol.

A propósito, é livre de controvérsias que deixar o sol brilhar sobre as operaçōes governamentais constitui um dos melhores antídotos à chaga da corrupção e da gestão pública displicente, porquanto os atos de ofício que lhes dão causa dissimulam-se no aparelho governamental e dificilmente aparecem na claridade do dia. ${ }^{354}$

A função dissuasória e ética da transparência já era percebida por Jeremy Bentham, para quem, quanto maior a quantidade de tentações às quais o exercício do poder político é exposto, mais necessário se torna dar àqueles que o detém os mais fortes motivos para resistir a elas, não havendo razão mais constante e universal que não a vigilância do público. ${ }^{355}$

A transparência, por si mesma, é um fator de controle substancial, ao reduzir a assimetria de informações na relação de delegação entre autoridades (agentes) e o povo (principal) e, portanto, o custo de transação de acordos corruptos. Uma vez informado, e bem informado, o cidadão desequilibra o foco de oportunidades que resulta da ignorância geralmente aproveitada pelos sujeitos desonestos. Não faltam comprovações empíricas sobre os impactos positivos da transparência no controle da corrupção e na promoção da boa governança. ${ }^{356}$ Correlacionando os índices de percepção da corrupção com o nível de abertura informacional dos governos, fica evidente a linearidade dos resultados.

Como afirma Roumeen Islam, governos que valorizam a transparência governam melhor porque a extensão dos dados públicos proporciona a existência de um mercado político menos corrupto e, por sua vez, mais eficiente. ${ }^{357}$

Caso notório de aperfeiçoamento neste sentido é o da Geórgia. Apontado pelo Banco Mundial como um dos países com melhor evolução contemporânea no combate à corrupção, tendo avançado significativamente mais que seus vizinhos

354 HORTA, Raul Machado. Improbidade e corrupção. Revista de Direito Administrativo, Rio de Janeiro, 236, abr./jun. 2004.

355 BENTHAM, Jeremy. Da publicidade. Revista Brasileira de Ciência Política, Brasília, n. 6, p. 277-294, jul. 2011.

356 Por todos: KAUFMANN, Daniel. Myths and realities of governance and corruption. Disponível em: <http://siteresources.worldbank.org/INTWBIGOVANTCOR/Resources/21_Governance_and_Corruption_Kaufmann.pdf>. Acesso em: 2 jan. 2018.

357 ISLAM, Roumeen. Do more transparent governments govern better? The World Bank, jun. 2003 (Policy Research Working Paper 3077). 
Armênia, Rússia e Azerbaijão, a Geórgia promoveu uma espécie de reforma sistêmica na estrutura e nos procedimentos de Estado, abordagem que Bo Rothstein chamou de Big Bang em função da magnitude e do sucesso na reversão do ciclo perverso de raízes corruptas do passado soviético para um ciclo virtuoso de governança. ${ }^{358}$

No ano de 2003, após uma sucessão de manifestações populares contra as eleições parlamentares, episódio conhecido como Revolução Rosa, levando à renúncia do então presidente Eduard Shevardnadze, o novo governo promoveu uma série de medidas com vistas a fortalecer a agenda anticorrupção. Além da condenação de agentes corruptos, desburocratização dos serviços estatais e profissionalização dos servidores, o governo da Geórgia tomou a transparência em sua forma literal, ao reconstruir as estações da polícia rodoviária, notável pela corrupção sistêmica de seus agentes, em estruturas de vidro, com o propósito de expor tudo o que ocorresse ali dentro. Considerada radical por alguns, a reforma teve inequívoca eficácia simbólica e dissuasória sobre aqueles que pretendessem engajar-se em atividades ilícitas. A propósito, no intervalo de 2003 até 2017, a Geórgia subiu extraordinárias 82 posições no índice de percepção da corrupção da Transparência Internacional, demonstrando uma transição relativamente rápida (13 anos) nos ciclos de governança. ${ }^{359}$

Mais do que evidenciar um caso de sucesso no controle da corrupção, a Geórgia fornece um exemplo contundente de como mudanças exclusivamente incrementais são insuficientes para a alteração de equilíbrios negativos de governança, não prescindindo de medidas cujo alicerce seja, dentre outros, a transparência, ou, o olho cintilante do povo sobre os agentes públicos.

Por outro lado, retomando um assunto já abordado exaustivamente, a transparência fortalece a confiança. Na medida em que os cidadãos se sentem envolvidos na circulação de informações e de conhecimento, estabelecem uma nova relação com seus governantes. Não vão querer se apropriar do poder no sentido de tomá-lo ou comandá-lo, senão de conduzir sua redefinição e fazê-lo funcionar de outra maneira. Vale lembrar que uma dose de desconfiança é saudável à democracia, porém apenas quando não assentada na ignorância. Penso que o bom ambiente institucional e político é fundado nessa espécie de desconfiança democrática,

358 BO ROTHSTEIN. The quality of government. Corruption, social trust and inequality in international perspective. The University of Chicago Press, 2011.

359 ROSENBERG, Steve. Georgia: are glass-walled police stations enough to tackle corruption? BBC News, 10 july 2013. Disponível em: <http://www.bbc.com/news/world-europe-23231993>. Acesso em: 8 fev. 2018. 
-• Finanças públicas: travessia entre o passado e o futuro

vale dizer, na atenção constante à atuação daqueles a quem conferimos parcela de poder e recursos públicos. Bentham é mais categórico: de quem nós deveríamos desconfiar, se não daqueles a quem é conferida autoridade, com grandes tentações de abusar dela? 360

A solução dos problemas mais profundos do Brasil passa pela forma como as instituições públicas lidam com a população. Elevar o nível de transparência é, portanto, um dos mais importantes e prementes desafios da administração e da sociedade. Mas em que sentido?

O desenvolvimento das tecnologias de informação e comunicação tem colaborado significativamente com a expansão da quantidade de dados disponíveis através de portais e outras ferramentas de acesso aos atos, procedimentos, contratos, registros e processos da administração. Pode-se dizer que jamais o cidadão esteve tão bem munido de insumos que dizem respeito à coisa pública. Esta é uma constatação positiva, bem como necessária à qualidade democrática que estamos buscando, mas não é suficiente.

A despeito do potencial difusor, a internet não tem proporcionado a concomitante facilitação das informações (e-readiness) e capacitação (e-skilling), tanto daqueles que disponibilizam os dados, quanto dos eventuais cidadãos-usuários.

Neste contexto, a transparência é muitas vezes confundida com a mera divulgação de informações, de modo que sua colocação em um ambiente eletrônico minimamente acessível eliminaria o ônus de tornar esta informação compreensível ao público a que se destina. Nesta concepção, a ideia de transparência seria um gatilho automático da crítica social democrática, o que é um equívoco.

Assim, a preocupação central no tocante à visibilidade do governo atualmente não parece mais estar atrelada tanto à disponibilidade dos dados (nos ângulos da transparência ativa ${ }^{361}$ e passiva ${ }^{362}$ ), embora este aspecto ainda conserve certas deficiências, ${ }^{363}$

360 BENTHAM, Jeremy. Da publicidade. Revista Brasileira de Ciência Política, Brasília, n. 6, julho, p. 277-294, 2011.

361 Informaçôes disponibilizadas independentemente de requisição por parte do cidadão interessado (art. $8^{\circ}$, da Lei n. 12.527/2011). Conforme a Lei de Acesso à Informação, a disponibilização de diversos tipos de dados na internet se tornou obrigatória para os órgãos públicos, o que inclui informações concernentes a procedimentos licitatórios, respectivos editais e resultados, bem como todos os contratos celebrados.

362 Direito de o cidadão realizar uma solicitação de acesso à informação, estabelecendo mecanismos para os cidadãos enviarem requisiçôes diretamente ao governo, com regras claras e prazos-limite de resposta previamente estipulados.

363 Estudo do Centro de Tecnologia e Sociedade da FGV Direito Rio produziu uma avaliação concernente aos cinco anos de vigência da lei de acesso à informação, buscando responder à 
mas diz respeito, principalmente, à legibilidade das informações. É dizer, à compreensibilidade dos dados que são revelados via plataformas públicas. O direito de saber se relaciona com a tendência à publicação cada vez mais volumosa de documentos e estatísticas. O problema então passa a ser o do afogamento em uma massa inflexível de informaçóes, geradora de um novo tipo de opacidade.

Do dever constitucional de publicidade (art. 37, $\$ 1^{\circ}$, CRFB/88), deflui a obrigação de fornecer informaçóes que sejam, ao mesmo tempo, tempestivas, completas, claras e inferíveis (capacidade de inferir algo sobre os dados). Assim, o direito de saber só tem sentido se figurar ao lado do direito de compreender, de semelhante importância, que destrava a capacidade do cidadão de participar e controlar.

$\mathrm{Na}$ relação republicana estabelecida entre governantes e governados, o primeiro é obrigado a render contas sobre o que está fazendo, mas também deve encontrar um modo de fazê-lo que possa ser entendido pelo principal. Os agentes (públicos) não podem lavar as mãos e simplesmente esperar que os indivíduos tenham a capacidade de, por si mesmos, agregar diferentes fontes de dados para ver como seus mandatários estão agindo: estes têm o dever democrático de dizer, explicar e assegurar que entendemos aquilo que nos foi transmitido.

Quantos cidadãos conseguem, com razoável facilidade, acessar os sistemas de contabilidade pública, os SIOPE, SIOPS, SIAFI e identificar o montante de recursos financeiros que estão sendo destinados à saúde e educação no orçamento? Quantos estão habilitados a decifrar irregularidades ao analisar o Relatório Resumido de Execução Orçamentária (RREO) ou no Relatório de Gestão Fiscal (RGF)? Caso estejam habilitados a decodificar as informações e entendê-las, é possível realizar comparações com anos anteriores, para aferir o desempenho das finanças do Estado? E quanto às políticas públicas, quantas fases de implementação de determinada ação política podemos acessar? Que indicadores estão disponíveis?

Infelizmente, além do evidente déficit cognitivo, fruto do paupérrimo sistema de educação pública, somado à inexistência de matérias específicas dirigidas ao exercício da cidadania (educação cívica), o Brasil ainda carece de uma depuração adequada dos dados públicos, o que resulta em uma transparência controversa, que é abundante, porém inócua; e um accountability vertical insatisfatório. Esta dura

questão se a opacidade estaria cedendo à transparência. O estudo conclui, no entanto, que o comprometimento com o acesso à informação no Brasil é fraco e incipiente em todas as instituições públicas brasileiras, com a parcial exceção do executivo federal. (MICHENER, Gregory; CONTRERAS, Evelyn; NISKIER, Irene. Da opacidade à transparência? Avaliando os cinco anos da lei de acesso à informação no Brasil. FGV-Direito, 2016. Disponível: <https:// portal.fgv.br/sites/portal.fgv.br/files/transparencyandopacity_pt.pdf>. Acesso: 8 fev. 2018). 
realidade sobressai particularmente nos governos locais, que, inobstante a criação dos portais eletrônicos exigidos legalmente, mantém uma estrutura ineficiente que atravanca o acesso e a compreensão dos dados. Sendo a unidade política mais próxima do cidadão, esperava-se que as municipalidades fossem mais sensíveis à sociedade e fáceis de se responsabilizar e que, portanto, recebessem maiores incentivos para atuar em conformidade aos critérios de governo aberto. Contudo, não é o que a realidade apresenta. ${ }^{364}$ Os municípios interioranos, que constituem maioria dentre as 5.528 cidades brasileiras, quando disponibilizam informações, o fazem de forma ilegível, desagregada e incompleta.

Vale lembrar que a adoção da linguagem compreensível, também denominada de linguagem cidadã, não constitui um indulto ou obséquio das autoridades, mas um dever previsto, primeiro, na Constituição Federal e, depois, na lei de acesso à informação.

O ponto aqui é simples: paralelamente à maior disponibilidade, as instituições ainda se encontram opacas aos olhos dos cidadãos, os processos de tomada de decisão inacessíveis e as políticas públicas implementadas mais difíceis de se avaliar. No cerne disso, encontra-se o obstáculo da ilegibilidade, desafiando a possibilidade de os cidadãos tomarem conhecimento por si mesmos do funcionamento das instituições estatais.

Não há, por consequência, nada de mais urgente na agenda de reforma do modelo de governança brasileiro que tornar as instituiçôes e mecanismos de decisão mais legíveis, para espantar a escuridão que destrói a capacidade do povo de converter-se em ator crítico de sua história.

Para tanto, sintetizo a seguir algumas propostas de aperfeiçoamento ao sistema de transparência pública brasileiro, buscando ir além do palpite legislativo e incrementalista, com o propósito de alcançar um padrão adequado de legibilidade dos dados públicos. Evidentemente, não pretendo esgotar o assunto, tampouco presumir que as medidas aqui aventadas irão resolver completamente o problema, embora acredite que, adotando-as, possamos dar largos passos em direção à abertura do governo. Nessa linha de pensamento, segmentei a análise das propostas em dois planos de reforma. O primeiro, composto por medidas endógenas, tomadas pelo estado e a ele vertidas, com o propósito de promover a simplificação do conteúdo e do acesso às informações; o segundo, fundado em medidas exógenas,

364 Vale lembrar que os municípios estão constitucionalmente obrigados a disponibilizar as suas contas, anualmente, por 60 dias, para exame e apreciação dos contribuintes, que podem questionar-lhes a legitimidade. (art. $31, \S 3^{\circ}$, da CRFB/88). 
referentes ao plano social, ou seja, à forma como a sociedade lida e aperfeiçoa a transparência pública.

No plano endógeno, iniciaria com o aumento da compreensibilidade do projeto orçamentário. Embora o Brasil esteja relativamente bem avaliado nos índices de abertura orçamentária, como o Open Budget Index (77/100), são reiteradas as recomendações no sentido de apresentar mais informações sobre a classificação das despesas e das receitas de anos futuros. De fato, dificilmente consta nas leis orçamentárias dos entes federativos os valores estimados para os exercícios subsequentes, conforme exige de forma expressa a Lei de Responsabilidade Fiscal, informação indispensável à avaliação do planejamento da gestão, sem a qual resta pouco provável anteciparmos a sustentabilidade - e a lógica - de determinadas políticas públicas.

Outro centro de opacidade financeira diz respeito à revelação das assim chamadas despesas extraorçamentárias (off budget expenditures), já abordadas superficialmente no início deste livro, referentes à renúncia de receita, especialmente os benefícios tributários concedidos a grupos específicos do empresariado e corporações com influência pesada sobre o centro de decisões políticas. Estas despesas, sujeitas ao crivo dos caçadores-de-renda, especializados em desvirtuar a alocação dos recursos coletivos, carecem da transparência adequada à avaliação de sua viabilidade, sustentabilidade, eficiência e honestidade.

Mas, principalmente, ressente-se da publicação de relatórios e gráficos de simples entendimento ao cidadão leigo, que lhe permita entender as finanças da União, do Estado ou do Município onde vive. Um exemplo eloquente desta necessidade encontra-se na infinidade de classificadores presentes na lei orçamentária, que praticamente inviabilizam uma análise desburocratizada das alocações públicas. Simplificar a norma orçamentária implica, portanto, sintetizar estes classificadores, apresentando os gastos por programas e ações claramente identificáveis, com os valores previstos para o exercício em curso e a estimativa para os próximos. Com as ferramentas proporcionadas pela internet, não há desculpas para que este trabalho de facilitação não seja empreendido.

No campo das contratações públicas, que concentram a maior parcela de recursos e, portanto, de oportunidades para a corrupção, a claridade é essencial e deve acompanhar todas as etapas de aquisição. Uma das questôes essenciais que integra este cenário é a (des)obediência à ordem cronológica dos pagamentos ou exigibilidades, de acordo com a execução dos respectivos contratos, conforme previsto no art. $5^{\circ}$, da Lei Geral de Licitações e Contratos Administrativos. ${ }^{365}$ Em tese,

365 Art. $5^{\circ}$ Todos os valores, preços e custos utilizados nas licitaçôes terão como expressão monetária a moeda corrente nacional, ressalvado o disposto no art. 42 desta Lei, devendo cada 
a observância dessa ordem de pagamentos, pelas fonte diferenciada de recursos, inviabilizaria a escolha puramente discricionária do gestor sobre quem irá pagar primeiro, dando ensejo à cobrança de facilidades (propinas) em ordem a permitir que determinados fornecedores "furem a fila" e recebam de forma antecipada àqueles de direito. $\mathrm{Na}$ essência, deveria constituir uma garantia legal ao contratado e ao cidadão de que não haverá perseguições ou favoritismos, e que os privilégios serão bloqueados. Na prática, entretanto, o controle da obediência à ordem de pagamentos é extremamente frágil, quiçá inexistente, pois não há qualquer sistema que possibilite a divulgação da respectiva lista de credores na rede, o que deveria ser feito de forma ampla e irrestrita. O resultado é intuitivo: é comum que gestores deixem de liquidar serviços prestados ou bens adquiridos, obstando que os respectivos fornecedores entrem na lista de credores do ente público, de sorte que possam oferecer facilidades diante das dificuldades criadas e, ao mesmo tempo, passem desapercebidos sob o controle externo e social.

No plano das políticas públicas, dois pontos merecem destaque.

Primeiro, precisamos urgentemente destravar uma política que dê transparência e integridade às relações entre a esfera pública e a esfera privada, estabelecidas através das práticas de influência governamental conhecidas como lobby. Os grupos de pressão que atuam direta ou indiretamente no parlamento, buscando influenciar decisões administrativas ou legislativas, através de diferentes formas de inputs técnicos ou não, são inegavelmente importantes ao funcionamento saudável da democracia. É do jogo político-democrático ter interesses concretos e poder reivindicá-los junto aos tomadores de decisão. No entanto, tal como qualquer espécie de relação ou exercício de poder que envolva custos e transações, o lobby que não encontra limites na transparência tende ao abuso e à corrupção de sua forma. Esta é uma questão comum às democracias contemporâneas, contudo, os casos recentes de compra e venda de medidas provisórias e programas de governo (refis, por exemplo) revelados pelas operaçóes policiais, no Brasil, descortinaram um lobby obscuro, bem como um sistema político completamente permeável à captura pelo poder econômico. O problema está entrelaçado ao capitalismo politicamente orientado a que se referia Raimundo Faoro (crony capitalism), no seio do qual vale mais a costura de relações políticas estratégicas do que a produtividade para obter

unidade da Administração, no pagamento das obrigações relativas ao fornecimento de bens, locaçōes, realização de obras e prestação de serviços, obedecer, para cada fonte diferenciada de recursos, a estrita ordem cronológica das datas de suas exigibilidades, salvo quando presentes relevantes razôes de interesse público e mediante prévia justificativa da autoridade competente, devidamente publicada. 
desenvolvimento. Justamente por isso é que há pouquíssimo interesse político em jogar alguma luz sobre as práticas opacas de lobby e alterar o status quo extremamente rentável, como fizeram a Eslovênia, Irlanda, Áustria, Polônia e o Reino Unido. ${ }^{366}$ Uma política satisfatória de transparência na interação entre o poder econômico e o poder político, contudo, é a forma mais recomendada para converter possíveis promiscuidades fisiológicas em um ambiente realmente democrático. Do lado dos grupos de pressão, é importante esclarecer os procedimentos utilizados, através do registro dos lobistas - nome que já está associado à corrupção, que entidades eles representam, com que recursos e sob quais propósitos agem. Do lado dos parlamentares e tomadores de decisão, é necessário promover a divulgação de informações sobre encontros realizados, além da revelação de eventuais interesses particulares que possam conflitar com a posição pública exercida (participações societárias, investimentos, relação de parentes com empresas etc.). ${ }^{367}$ Sabemos que apenas a regulamentação não promoverá esta "virada-democrática" no jogo de interesses, razão porque, sobretudo no tocante aos agentes políticos, uma ação coletiva é fundamental para pressioná-los a publicar proativamente tais informações. ${ }^{368}$

O segundo ponto concerne a um aspecto que será explorado mais detidamente no tópico sobre accountability que encerrará este livro, porém, uma abordagem inicial é necessária para que seja possível apresentar os contornos da proposta de desenvolvimento da transparência aqui tratada. Como se verá, ao evoluir de um paradigma racional-burocrático para uma noção gerencial, na transição da década de 1980-90, a avaliação de políticas e programas governamentais deveria ultrapassar o apego aos ritos e formas, para se concentrar na eficácia e efetividade dos resultados, isto é, nos impactos reais que determinada ação pública tem na vida dos cidadãos para os quais se destina. Assim, a boa-governança das políticas públicas

366 MULCAHY, Suzanne. Lobbying in Europe. Hidden influence, privileged access. Transparency International, 2015.

367 A propósito, tramita na Câmara dos Deputados o projeto de lei n. 1.202/2007, cujo propósito é regulamentar a prática do lobby na administração pública federal, impondo às pessoas físicas e jurídicas, organismos e entidades que pretendam influenciar decisões legislativas ou administrativas, obrigaçôes de transparência, como o credenciamento periódico, gerido pela Controladoria-Geral da União, a indicação de representantes que irão atuar em nome das entidades cadastradas, além do dever de envio de informaçôes sobre interesses e recursos ao Tribunal de Contas da União.

368 Em fevereiro de 2018, o Ministério do Trabalho incluiu a atividade de lobista na lista da Classificação Brasileira de Ocupações. No cadastro oficial, a pasta reconhece a categoria como profissional de relações institucionais e governamentais e aponta que se enquadra na função o "defensor de interesses". 
pressupõe a existência de metas e indicadores que permitam assegurar transparência aos resultados. Estes dados sobre o desempenho público (performance data), ao demonstrar à sociedade o que o governo está realmente fazendo e em que medida as demandas cidadãs estão sendo atendidas, aumenta os meios de fiscalização social, ao passo que diminui as oportunidades para que o Estado atenda interesses específicos, conservando privilégios. Nessa linha de pensamento, seria salutar estabelecer um banco centralizado de indicadores nas esferas políticas (União, Estados e Municípios), expondo os critérios objetivos que norteiam o controle de fato sobre os resultados alcançados. A propósito, os Tribunais de Contas são potenciais auxiliares à consolidação dos indicadores, na medida em que baseiam suas atividades principalmente no acesso a informações relacionadas às finanças públicas e à condução dos negócios do Estado. Além de auxiliar na construção das metas e inserir o seu atendimento nas matrizes de auditoria, caberia ao órgão de controle externo assegurar que os dados reflitam a realidade concreta referente à implantação das políticas públicas, e que sejam de fácil entendimento pela população. Experiência semelhante, baseada em um sistema de indicadores estratégicos, pode ser observada, por exemplo, na Hungria, por intermédio da instalação de indicadores-chaves nacionais (key national indicator). ${ }^{369}$

Para encerrar a perspectiva endógena de reforma em benefício da transparência, não se pode ignorar o fato de que as deficiências na implementação da Lei de Acesso à Informação no Brasil se devem, em larga medida, à ausência de supervisão do seu cumprimento nos organismos públicos. Até 2017, apenas 10 capitais brasileiras faziam referência a entidades responsáveis pela fiscalização e enforcement da LAI. A existência de corpos que promovam este monitoramento oferece fortes incentivos externos para o cumprimento da transparência. Em função disso, creio que concretizaríamos com mais vigor o acesso à informação caso existisse um organismo especializado de efetivação da Lei n. 12.527/2011, a exemplo do conselho de transparência e bom governo espanhol, órgão vinculado ao Ministério da Fazenda e Administração Pública, com a finalidade de promover a transparência da atividade pública, velar pelo cumprimento das obrigaçôes de publicidade e salvaguardar o exercício do direito de acesso à informação ${ }^{370}$ ou como a Autoridade Suprema para Transparência na Vida Pública (Autorité pur la transparence de la vie publique), recentemente criada na França. ${ }^{371}$

369 GOMES, Marcelo Barros et al. Accountability e transparência na implementação da agenda 2030: as contribuições do Tribunal de Contas da União. Revista do TCU, maio/ago. 2016.

370 Conforme preceituam os arts. 33 e 34 da Ley n. 19, de 9 de dezembro de 2013.

371 Conforme o art. 25 do título II da Lei n. 2016-1961, de 9 de dezembro de 2016, também conhecida como Sapin II. 
No plano exógeno, tratamos das medidas que partam da própria sociedade civil organizada, e não da estrutura de estado, embora destinadas a tornar mais visível essa última. Do ponto de vista da legibilidade, é crucial restabelecer o papel revolucionário da imprensa em termos de construção da visão crítica do cidadão, colocando-o a par dos fatos que se intenta esconder e dos dados que são complexos demais para uma análise isolada. Refiro-me ao restabelecimento porque, atualmente, muitos veículos de comunicação em massa se encontram absortos pelo sensacionalismo e pela visão estreita da ideologia de lucro que guia seus editoriais. Afora o problema iminente das notícias falsas (fake news), o caráter tradicionalmente denunciativo e independente da imprensa cedeu lugar à especulação, à descredibilidade e à relação estreita demais com atores que pretendem apenas manipular a opiniāo pública. É oportuno lembrar que as primeiras manifestações de controle social ocorreram por intermédio da transparência fornecida pela imprensa, que deve retomar a autonomia original para continuar reverberando a vigilância popular.

Em um ambiente ainda mais diretamente associado ao povo, deve-se salientar a relevância das organizações não governamentais nas tarefas de sistematizar, decifrar e disseminar os dados públicos, quando estes não se encontram em formato adequado ao manejo pela sociedade em geral.

Apresentadas aquelas que entendo serem as medidas mais iminentes na agenda política que procura colocar o governo à vista do povo, não poderia deixar escapar uma ressalva importante, que já abordei e agora reitero: o sucesso de qualquer medida destinada ao aprimoramento do acesso à informação pública não prescinde de uma sociedade civil forte. Nas palavras de Stuart Mill, a publicidade não constituirá nem um impedimento ao mal, nem um estímulo ao bem, se o público não quiser ver o que está acontecendo. ${ }^{372}$ De fato, um aparato de transparência instrumental, por mais qualificado que seja, pode não ter impacto - ou, como se dizia lá no meu interior, ser santo de prostíbulo - caso a população feche os olhos deliberadamente a atuação pública. Pode parecer, a priori, um mero apelo intuitivo desta autora, mas a hipótese é comprovada por estudos que demonstram, por exemplo, que a implementação de leis de acesso à informação foi deficitária em países onde a norma foi adotada como resultado de um plano de reforma vinda dos governantes (p.ex.: Albânia), ou como produto de lobby das elites (p.ex.: Peru). Em contraste, em países onde coalizões da sociedade civil pressionaram pela aprovação de leis

${ }^{372}$ MILL, John Stuart. Consideraçôes sobre o governo representativo. Brasília: Editora UnB, 1984. 
- Finanças públicas: travessia entre o passado e o futuro

que previssem o direito de saber (p.ex.: Eslováquia, Romênia e Bulgária), a norma surtiu efeitos positivos na abertura do governo. ${ }^{373}$

Enfim, a limitação da transparência em uma era de crescente polarização e o temor legítimo de que os dados sejam menos atrativos em uma nova era de pós-verdade diante das fake news não é a resposta correta. A melhor forma de combater os ciclos desastrosos de desconfiança é que os governos publiquem informações cada vez mais completas e legíveis sobre as etapas de sua atuação, apresentando justificativas claras e congruentes sobre suas decisões.

373 KOCAOGLU, Nurhan; FIGARI, Andrea. Using the right to information as an anti-corruption tool. Berlin: Transparency International, 2006. 